\title{
Espaços formais de aprendizagem: possibilidades para a ambientalização.
}

Formal learning spaces: possibilities for environmentalization.

DOI: $10.54019 /$ sesv2n3-009

Recebimento dos originais: 05/07/2021

Aceitação para publicação: 20/08/2021

\section{Edicarlo Ferreira}

Doutorando no curso de Ensino de Ciências e Matemática, na Universidade Cruzeiro do Sul, de São Paulo.

E-mail: prof.edykarloquimica@gmail.com

\section{Rita de Cássia Frenedozo}

Doutora, professora e orientadora no curso de Pós-Graduação em Ensino de Ciências e Matemática, na Universidade Cruzeiro do Sul, de São Paulo

E-mail: ritafrenedozo@yahoo.com.br

\section{RESUMO}

Este trabalho teve como objetivo fazer uma revisão de literatura sobre a temática ambiental no ensino formal realizado no Estado de São Paulo. O problema de pesquisa é: como está sendo trabalhada a educação ambiental nos espaços formais de ensino e aprendizagem? Objetivos específicos: investigar a adoção de atividades educativas ambientais por parte das escolas públicas; perceber como as iniciativas ambientais conduzidas nas escolas públicas podem impactar na conduta cidadã. Para a revisão de literatura adotou-se nesse estudo a Revisão Bibliográfica Narrativa. O levantamento bibliográfico considerou artigos publicados entre 2015 e 2020 nas bases de dados (Google scholar, na plataforma Scielo e no banco de teses e dissertações da CAPES). Para a busca, foram utilizadas as palavras-chave: Ambientalização, Espaço Formal e Ensino. Há escolas apropriadas com locais disponíveis a cumprir o estabelecido nas Diretrizes Curriculares Nacionais Para a Educação Ambiental, permitindo o desenvolvimento de projetos, com espírito participativo e coletivo.

Palavras-chave: Ambientalização, Espaço Formal, Ensino.

\section{ABSTRACT}

This work aimed to make a literature review on the environmental theme in formal education held in the State of São Paulo. The research problem is: how is environmental education being worked on in formal teaching and learning spaces? Specific objectives: to investigate the adoption of environmental educational activities by public schools; to understand how environmental initiatives conducted in public schools can impact on citizen behavior. For the literature review, the NarrativeBibliographic Review was adopted in this study. The bibliographic survey considered articles published between 2015 and 2020 in the databases (Google scholar, the Scielo platform and the CAPES thesis and dissertation database). For the search, the Keywords were used: Environmentalization, Formal Space and 
Teaching. There are appropriate schools with available places to comply with the National Curriculum Guidelines for Environmental Education, allowing the development of projects, with a participatory and collective spirit.

Keywords: Environmentalization, Formal Space, Teaching.

\section{INTRODUÇÃO}

A educação contemporânea deve assumir uma concepção mais ampla, usando a educação informal e não formal como complemento à educação formal. As expressões formal, não formal e informal surgiram a contar da década de 1960, ancorada na referência do espaço escolar. As aprendizagens formais seriam as realizadas dentro do ambiente escolar e as conduzidas fora do espaço seriam as não formais e informais. Os espaços não formais podem ser museus, centros culturais e Organizações Não Governamentais (ONGs) (GOHN, 2016).

A expressão 'ambientalização', segundo Lopes (2006), é um neologismo das ciências sociais, designando novos fenômenos, ou percepções desses, sob uma perspectiva processual. Dentro da sociedade, agrega a grandeza histórica, adjunta à constituição de novos fenômenos, em uma assumpção dos diferentes atributos da questão pública ambiental. E nesse ínterim, a ambientalização curricular surge como um modo de entender o ambiente inserido em sua ótica cultural e política, considerando que se articula ao conceito curricular, considerando que o currículo é um artefato social.

De acordo com Soares e Frenedozo (2019, p. 98), "surge no campo educacional uma tendência de inserir debates sobre a questão ambiental nas instituições de ensino, dando origem ao termo conhecido como ambientalização curricular". Percebe-se que o termo é algo novo e passível de discussão. Em sua tese de doutorado, Miyazawa (2018, p. 56) afirma que "ambientalizar o ensino significa inserir a dimensão ambiental onde ela não existe ou está tratada de forma inadequada". Portanto, é preciso haver um compromisso sério entre os envolvidos neste processo.

A Educação Ambiental é vital na elaboração de significados e ações que sobrelevam a equidade e a redução do consumismo de produtos industrializados, respaldando a almejada sustentabilidade. Na visão de Oliveira e Neiman (2020), objetiva conscientizar as pessoas de que as questões ambientais se vinculam às suas rotinas e que a resolução de tais questões solicita o comprometimento e a 
cooperação de todos, desenvolvendo posturas cidadãs e sustentáveis. Alves (2014) salienta que apesar das 'boas intenções' as atividades antrópicas degradam a natureza e não propõem soluções concretas quanto ao iminente colapso ambiental, essa seria, sem dúvida, a temática mais sensível e urgente da contemporaneidade.

Para Inocêncio (2012), a EA surge como uma área de conhecimento capaz de atuar sobre o conflito civilizatório, maior que o ambiental. Apesar de políticas educacionais existirem, é frequente a visão convencional de transmitir conteúdos, com atividades isoladas, e não em prol da transformação social. Dias e Bomfim (2011) classificam a EA em Conservadora e Crítica, a primeira voltada para mudanças de comportamento e atitude, e a segunda problematizaria as reais raízes do problema. As Diretrizes Curriculares Nacionais para a Educação Ambiental (DCNEA), Resolução no 2 (BRASIL, 2012), considera o trabalho, a produção e o consumo vinculado às questões ambientais, ressaltando no artigo $5^{\circ}$, que a EA não é uma atividade imparcial, e sim envolta em valores e visões de mundo e, assim, assume na prática educativa suas dimensões política e pedagógica. Ainda, ressaltam uma abordagem interdisciplinar e transversal, não adstrita à uma disciplina, e sim, consoante 0 artigo $6^{\circ}$, superando a visão despolitizada, acrítica, ingênua e naturalista.

Segundo Ruscheinsky (2014), a ambientalização curricular é uma maneira de inserir a temática do ambiente no currículo escolar, conectado à práxis de formação do ensino superior, desde o ano 2000. Esse é um processo permanente e dinâmico, um compromisso institucional e transversal quanto ao ensino, pesquisa, extensão e gestão, integrando os setores e a comunidade universitária (FIGUEIREDO; GUERRA; CARLETTO, 2014).

As políticas públicas produzem, a contar dos pressupostos admitidos, como um direito de todos a educação que considere a reflexão crítica do meio ambiente, e é função da universidade possibilitar tais espaços, pautados na ética e na integridade ambiental. No que concerne à formação docente, a formação inicial é capaz de compor um caminho para construir um educador que leia e interprete as necessidades do seu espaço e planeje ações contemplando o ambiente em suas multíplices dimensões. Destarte, observa-se um amparo legal quanto à necessidade de abordar esse tema, apesar de a EA não se restringir à esfera do 
ensino formal, as escolas ainda são o espaço onde os indivíduos passam parte de seu tempo, formam-se enquanto sujeitos, elaboram conhecimentos, experimentações e visão crítica, de onde advém a necessidade de pontuar o assunto em tais espaços, exercendo a cidadania. A falta de capacitação dos professores corrobora a questão da formação inicial, para a qual as DCNEA, no artigo $11^{\circ}$, dispõe sobre a necessidade de uma formação inicial e continuada para a temática socioambiental (BRASIL, 2012).

Os maiores desafios da Educação Ambiental residem no baixo estímulo à pesquisa e à não integração do corpo docente, ou seja, basicamente falta de informação, investimento e capacitação. Nesse seguimento, atividades de campo e projetos ambientais interdisciplinares poderiam ser bastante promissores. As crianças poderiam adquirir hábitos ambientalmente adequados, tomando por exemplo seus professores, não só os de ciências, e levando tais hábitos para sua casa e seus familiares. O docente deve compreender da responsabilidade que assume em uma sala de aula, e fora desta também afeta francamente seus alunos, especialmente as crianças. Para tanto, uma vez que nem todos os professores têm formação em ciências, são necessários cursos de capacitação para docentes, permitindo que ensinem os preceitos básicos, e com a continuidade dos cursos, possam se aperfeiçoar (REIS; SEMÊDO; GOMES, 2012).

De acordo com Sauvé (2016, p. 290-291) torna-se necessário uma Educação Ambiental voltada para a aquisição de valores fortalecendo um relacionamento saudável e de respeito entre o ser humano e o meio ambiente:

A educação ambiental nos desafia em torno de questões vivas; ela responde às inquietudes maiores. Ela nos faz aprender a reabitar coletivamente nossos meios de vida, de modo responsável, em função de valores constantemente esclarecidos e afirmados: aprender a viver juntos - entre nós, humanos, e também com outras formas de vida que compartilham e compõem nosso meio ambiente. De uma cultura do consumismo e da acumulação, impulsionada por ideias pré-fabricadas, ela pode nos levar a uma cultura do pertencimento, do engajamento crítico, da resistência, da resiliência e da solidariedade.

Schanbach (2010) defende que para existir uma consciência ambiental, é 
necessário unir todas as áreas do conhecimento, afora a tecnologia, com vistas à uma ação integral do corpo social em defesa do meio ambiente. Embora todas as espécies tenham direito à vida, a espécie humana tem usado todas as demais em seu benefício próprio, manipulando os processos físicos e químicos e destruindo a natureza. Existem inúmeros desafios nesse seguimento, e um é elaborar uma nova ética cidadã, e a EA se faz obrigatória, curricularmente e nas capacitações, de modo que possam desafiarem-se e planejarem atitudes transformadoras.

Considerando essa conjuntura, ressalta-se o seguinte problema de pesquisa: como está sendo trabalhada a educação ambiental nos espaços formais? O objetivo geral é analisar a importância da educação ambiental formal na conscientização cidadã. Sobre a definição dos objetivos específicos, estabeleceu-se o seguinte: investigar a adoção de atividades educativas ambientais por parte das escolas públicas; perceber como as iniciativas ambientais conduzidas nas escolas públicas podem impactar na conduta cidadã; investigar questões positivas e negativas de experiências docentes com a temática ambiental, realizadas em espaços formais de ensino.

\section{A Educação Ambiental em Espaços Formais.}

A crise ambiental exige a participação de cada indivíduo e a escola é um ambiente distinto para formar cidadãos e desenvolver valores, no que concerne ao consumo e ao descarte de resíduos, embora ainda não tenha atingido seu potencial. No ensino formal, a EA é desenvolvida curricularmente em instituições públicas e privadas, sendo uma prática educacional permanente, inter e transdisciplinar, para qualquer nível e modalidade de ensino. Os conteúdos do nível fundamental e médio compõem-se nos PCNs, as políticas públicas também podem fomentar campanhas educacionais e informativas sobre o tema, como ações não formais, do mesmo modo que conteúdos que propiciem sensibilizar e capacitar a sociedade para as Unidades de Conservação, à sensibilização de agricultores e atividades voltadas ao ecoturismo (HENDGES, 2010).

Chassot (2003) salienta a escola como entidade formal, mas que em um mundo globalizado, exterioriza-se, parece haver uma contraversão no fluxo do saber, se dando da comunidade em direção à escola. Com efeito, a escola deve rever seu papel. Conquanto a ciência e a tecnologia são fundamentais ao crescimento econômico e social, as ciências influenciaram reformas educacionais, 
e os tópicos da educação ambiental, saúde e educação sexual passaram a incorporar os currículos como temas transversais (FERREIRA, 2013).

Um dos maiores desafios das escolas é o prosseguimento dos projetos propostos, e vários são os fatores influenciadores disso, como o tamanho da escola, a quantidade de estudantes e docentes, a disposição docente à capacitação, a boa vontade da gestão, alteração da rotina escolar, investimentos, entre outros. Além disso, muitas vezes os projetos não são aceitos por serem entendidos como uma ordem, uma tarefa a mais a ser cumprida pelos professores já sobrecarregados. Silva (2017) indica algumas técnicas multidisciplinares partindo de um Projeto Político-pedagógico que conjeture o espaço onde está inserido, o arrolamento dos problemas enfrentados pela comunidade, reflexão e busca de soluções, debates entre docentes e conteúdos, dentre outros. A depender do espaço escolar, o próprio espaço escolar seria útil, como áreas verdes, hortas, composteiras, reciclagem de lixo, trilhas ecológicas, recuperação de nascentes, entre outras.

Um projeto de educação ambiental só terá sucesso se for prazeroso, caso contrário nenhuma mentalidade individual será modificada. Cabe à escola a correlação entre as questões do ambiente e a realidade comunitária, de modo que os estudantes percebam o mundo real. Tal visão deverá se dar em todos os níveis de estudo, transformando-se a escola em um espaço social, no qual o aprendiz se sensibiliza com as crises ambientais, de modo que coloque em prática o que aprendeu na escola. Cidadãos responsáveis derivam de cotidianos escolares ambientalmente corretos (NARCIZO, 2009). As ações podem ser variadas, com palestras, oficinas e saídas de campo, sempre tendo em vista projetos que melhorem a qualidade de vida da comunidade.

\section{FORMAIS}

\section{AS EXPERIÊNCIAS DA EDUCAÇÃO AMBIENTAL NOS ESPAÇOS}

Apesar de divergências entre opiniões e localidades, a EA experimentada nas escolas ainda é hipotética, concretizada em projetos temáticos, e não articulada com o currículo e as demais áreas do conhecimento. Freitas (2016) desenvolveu uma pesquisa em 651 escolas da rede pública no Distrito Federal e na Secretaria de Educação, entre fevereiro e novembro de 2014, para observar a existência e a prática da EA. Observou-se que a EA permanece com as 
características da educação convencional, faltando reais alterações curriculares, e mantendo-se a fragmentação; a desarticulação entre ações; a descontinuidade dos projetos iniciados e a objeção dos docentes em trabalhar a EA. A interdisciplinaridade e a transversalidade são preceitos almejados nas atividades de EA em escolas, o que não foi possível de ser percebido na rede pública avaliada, provavelmente por formação continuada insuficiente, falhas nos planejamentos e restrição às disciplinas de Ciências Naturais, Geografia, Língua Portuguesa e Matemática, superficialmente, não alcançando a proposta. Também foram observados obstáculos, como o levantamento de informações, os contatos com as secretarias e falta de interesse da gestão escolar.

Viegas e Neiman (2015) conduziram uma pesquisa bibliográfica sobre práticas de EA no espaço de ensino formal, entre 2007 a 2012, e observaram que foram publicados 317 artigos, onde 34,4\% eram sobre concepções teóricas, $25,6 \%$ sobre práticas no ensino formal, $81,5 \%$ dos estudos foram em escolas públicas e 6,2\% em particulares, os demais em ambas. Quanto ao nível de ensino, $30,9 \%$ dos trabalhos se dedicava ao ensino fundamental, onde as DCNs advogam o ensino, e somente $2,5 \%$ ao ensino infantil, denotando reduzido interesse, o que contradiz o discurso geral da EA. Nessa questão, Montanhim, Caron e Cinquetti (2011) ressaltam a dificuldade de docentes da educação infantil em propor atividades ambientais para crianças, e a partir delas mudar as atitudes delas, sendo essa uma deficiência a ser sanada.

Um outro estudo analisou os trabalhos apresentados no IX Encontro de Pesquisa em Educação Ambiental (EPEA) em 2017, com 128 trabalhos aprovados, o Grupo de Discussão de Pesquisas (GDP) em EA e Contexto Não Escolar contou com doze estudos, somente 8,5\% do total, uma parte dos trabalhos dedicou-se às áreas ambientais protegidas, projetos de extensão em universidades, e outros pareciam não se enquadrar nos critérios de investigação. Também foram admitidos trabalhos sobre políticas públicas, sobrepostos a unidades de conservação e licenciamento ambiental, além de oficinas comunitárias e projetos municipais de educação ambiental. As reflexões realizadas permitiram observar que a EA tem se expandido anualmente, despertando novos estudos e alunos, cuja continuidade é significativa para a pesquisa em EA, uma área múltipla, que suporta distintas práticas pedagógicas, 
com vistas a superar a crise ambiental moderna (LOPES; BUENO; SAISSE, 2018).

Uma pesquisa foi conduzida com professores formados em Ciências Biológicas, Geografia, Química e Pedagogia, com tempo de profissão entre cinco e 25 anos. Os profissionais relataram dificuldades sobre o EA sob a perspectiva escolar, e os espaços não formais funcionavam como um suporte, também foi aventada a interdisciplinaridade, especialmente via resistência e outras disciplinas com a temática; a carga horária; os amplos conteúdos a serem cumpridos; e a falta de espaço apropriado nas escolas. A falta de atratividade para o estudante foi reiterada, o que corrobora a questão da falta de preparo do docente (MARTINS; TEIXEIRA; SOUSA, 2017). Isto posto, tais dificuldades culminam na superficialidade da educação ambiental. Aparentemente, a baixa efetividades das ações educativas relaciona-se à resistência ou desconhecimento da transversalidade e interdisciplinaridade. A ausência de espaço adequado nas escolas poderia ser complementada pelos espaços não formais, especialmente na área ambiental, Silva e Grynszpan (2015) defendem essa ideia, de forma que os espaços não formais ultrapassem as possibilidades que a educação formal permite, pois o tempo e o espaço seriam mais apropriados, contemplando mais transversalmente os assuntos. Nesse sentido as parcerias são primordiais.

No ano de 2020, durante a pandemia de COVID-19, a temática dos professores no ensino à distância tem se aviltado. Um ponto salientado é a falta de ferramentas necessárias ao EaD; quanto aos docentes, encontram-se sobrecarregados e com imensas dificuldades com as ferramentas disponíveis, especialmente na rede pública. Alves e Mamede (2020) investigaram a rede municipal em Campo Grande-MS e observaram que o acesso on-line não era tão frequente quanto imaginado, muitas vezes sendo os materiais impressos e retirados pelos alunos na escola; alguns docentes se sentiram desconfortáveis em usar suas mídias pessoais para as aulas; as devolutivas dos estudantes têm sido evasivas e levianas; e a questão da avaliação permanece obscura. Basicamente, o que se observa é a aplicação da mesma matriz presencial com recursos de tecnologia, talvez seja o momento de a contribuição da EA ser ativa na elaboração de relações sociais capazes de superar as desigualdades observadas.

\section{Metodologia}


Para o desenvolvimento desse estudo realizou-se uma revisão de literatura publicada de 2006 a 2020 nas bases de dados Google scholar, na plataforma Scielo e no banco de teses e dissertações da CAPES. Para a busca, foram utilizadas as palavras-chave: Ambientalização, Espaço Formal, Educação Ambiental e Ensino e suas correspondentes em inglês Environmentalization, Formal Space, Environmental Education and Teaching. Foram critérios de exclusão: artigos que não apresentaram contribuições significativas para este trabalho ou que abordavam o assunto de forma irrelevante.

Para a escolha dos artigos fez-se a leitura crítica, questionadora e seletiva das publicações selecionadas de forma a destacar os aspectos mais relacionados ao problema de pesquisa (BENTO, 2012). O referencial teórico é essencial para fornecer o embasamento teórico necessário à robustez do trabalho, permitindo a discussão de ideias entre os autores mais relevantes na área pesquisada. Segundo Martins e Pinto (2001), tal procedimento é essencial a compreensão de conceitos, bem como para a condução de novos estudos sobre o tema.

No que tange ao tipo de pesquisa, optou-se pela pesquisa qualitativa, um importante ponto de referência ao pesquisador, o qual é responsável pela pesquisa extensa e sua avaliação crítica (CAJUEIRO, 2012). Deste modo, um procedimento metodológico orientado por uma pesquisa qualitativa avalia as informações obtidas e é capaz de apresentar conclusões relevantes, de acordo com um dado problema de pesquisa pré-determinado (ROTHER, 2007).

A pesquisa qualitativa nesse estudo é exploratória, pois é o método que possui maior identificação com a metodologia de Revisão Bibliográfica Narrativa (Revisão de Literatura), cuja metodologia foi adotada para o desenvolvido deste artigo. Ressalta-se um importante conceito sobre pesquisa exploratória:

Pesquisa exploratória é quando a pesquisa se encontra na fase preliminar, tem como finalidade proporcionar mais informações sobre o assunto que vamos investigar, possibilitando sua definição e seu delineamento, isto é, facilitar a delimitação do tema da pesquisa; orientar a fixação dos objetivos e a formulação das hipóteses ou descobrir um novo tipo de enfoque para o assunto. Assume, em geral, as formas de pesquisas bibliográficas e estudos de caso. (PRODANOV; FREITAS, 2013, p. 51-52).

A metodologia de Revisão Bibliográfica Narrativa objetiva buscar em bases 
de dados, identificar os artigos, avaliá-los e proceder à sua discussão. Verifica-se que a Revisão Bibliográfica Narrativa, método de escolha adotado, visa a apreensão e a análise dos fundamentos de natureza científica, isto é, de trabalhos de impacto científico, publicado em periódicos, jornais e/ou outros meios científicos nacional e/ou internacional (DEMO, 2009; SOUSA et al. 2018).

\section{RESULTADOS E DISCUSSÃO}

Por meio da Educação Ambiental, há muitas possibilidades de se interferir no comportamento do ser humano de modo a contribuir para que este se torne crítico e consciente de seus atos. Um dos espaços em que há grande possibilidade de se trabalhar a Educação Ambiental é a escola, reconhecida como lugar privilegiado para a construção de diálogos, valores e princípios que auxiliam na formação discente.

Com base nos vinte trabalhos analisados percebeu-se algumas barreiras para não se trabalhar com a ambientalização nas escolas, destas barreiras, cinco trabalhos apontam para a resistência do professor em inserir a dimensão socioambiental em suas aulas, visto que estão acostumados a trabalhar 0 currículo de forma engessada e sem interesse em sair do comodismo, mas que é possível, desde que se trabalhe seriamente para isto. Em relação à falta de políticas públicas para a implementação de temas socioambientais nos currículos, dez trabalhos mostraram que pouco se tem feito nas últimas décadas e que são necessárias ações urgentes para que se consiga enxergar o meio ambiente como prioridade, sabendo que a relação deste com o homem é uma questão de vida. Dois trabalhos mostraram que é possível realizar a ambientalização em escolas e apontam possíveis caminhos para sua concretização. Um deles é a participação coletiva e ativa de todos os envolvidos no processo ensino e aprendizagem.

Ainda sobre a ambientalização, três trabalhos registraram a falta de interesse das equipes gestoras que não demonstraram interesse no desenvolvimento de projetos sobre ambientalização e que trabalham as questões ambientais com seu corpo docente apenas em datas comemorativas.

Contudo, esta revisão concluiu que o processo de ambientalização em espaços formais de ensino ainda é algo novo e passível de discussão. Com a participação mais efetiva dos docentes, o trabalho com a ambientalização mostra-se mais eficiente, visto que muitos professores apenas cumprem o disposto nos planos 
anuais de ensino.

Considerações Finais

De acordo com o exposto, existem escolas que dispõem de enorme potencial de apoio ao ensino formal, com espaços apropriados e parcerias com outros locais, de forma que podem cumprir o estabelecido nas DCNEA, incluindo observar a natureza, compreender as extensões éticas e políticas, desenvolver projetos e ações responsáveis quanto ao ambiente, realizar trabalhos coletivos, consolidando o espírito participativo e coletivo. No entanto, outras escolas e docentes identificam ser necessários trabalhos de capacitação, onde os próprios educadores conhecerão os espaços não formais de ensino ambiental, de forma a adotá-los na educação formal e não formal, beneficiando o ensino dos estudantes. A Educação ambiental vem sendo elaborada a partir de várias concepções e abordagens, com caminhos e modalidades distintas para o fazer educacional. Tal qual as demais áreas do saber, tem falhas e pode ser generalista, sem contribuir aos objetivos, embora represente a mudança e a inserção da extensão ambiental como um novo conceito. As práticas de EA, no espaço formal, mostram um contorno predominantemente público e voltado ao ensino fundamental, especialmente em algumas regiões do país, como a Sudeste. Tais práticas são propostas por pesquisadores, sendo apoiadas pelo governo ou pela iniciativa privada, as quais incluem alunos no espaço escolar. Destarte, deveriam incluir temáticas interdisciplinares e transversais, sob uma perspectiva crítica, vinculado ao planejamento metodológico de educação baseada em projetos, por exemplo. $\mathrm{Na}$ realidade, tais propostas ainda se mostram não integrais ou não reprodutíveis, com lacunas metodológicas e de execução do disposto na legislação no que tange à interdisciplinaridade. O conhecimento de tais práticas poderia ser um dos pressupostos fundamentais na avaliação do panorama acadêmico e científico, bem como um critério norteador aos especialistas da área.

O papel do educador, do professor, é crucial na EA, o qual deve abandonar o paradigma convencional de transmissão de conteúdo para adotar novas ferramentas de investigação, distintas técnicas dentro e fora da escola, como mídias sociais, trilhas e debates, com vistas a sensibilizar os estudantes para a proteção do meio ambiente. Enfrentar os problemas sociais é mais importante que a memorização de conteúdos, evitar o desperdício de água é mais relevante que 
notas elevadas. Não se pode separar a vida da natureza, todos devem se comprometer com o mundo. Só assim, a educação poderá transformar o mundo, e para tanto, os docentes devem se preparar para as dificuldades contemporâneas, e esse dever não é dos professores de ciências ou de biologia, mas de todos, de forma a entender-se como partícipe do ambiente. A proposição de soluções aos problemas, de forma a respeitar a própria natureza e não gerar mais danos a longo prazo é urgente, e é na juventude acadêmica que estas soluções poderão surgir.

Nesse ínterim, o espaço escolar é o lugar onde o aluno reflete sobre os conceitos e os conteúdos, mas também deve ser desafiado à ação, ampliar suas interações, assumir uma posição crítica. O uso das tecnologias e mídias sociais também pode ser uma alternativa para incluir os jovens em ações pedagógicas e ambientais, além da necessidade de incluir os próprios professores nessa temática, os quais mostram muita resistência, mas que poderia ser um dispositivo de interrelacionamento valoroso. Com efeito, a sociedade, o Governo e a escola devem firmar parcerias para responder à demanda ambiental, as disparidades e os casos exitosos devem ser divulgados; bem como a alteração dos espaços criando ambientes educativos; o investimento na capacitação dos recursos humanos, infraestrutura, ferramentas e suporte que possam manter a EA como uma extensão primordial da educação. Assim, em síntese, o presente estudo analisou a educação ambiental em espaços formais, especialmente na escola pública. Sugere-se, ainda, que outros estudos sejam desenvolvidos para discutir e fortalecer o tema da presente pesquisa, levando-se em consideração a evolução da sociedade e do próprio ambiente, bem como os principais autores da área da educação e da educação ambiental. 
Referências

ALVES, J. E. D.. População, desenvolvimento e sustentabilidade: perspectivas para a CIPD pós2014. Revista Brasileira de Estudos de População, v. 31, n. 1, p. 2019-230, 2014. ISSN: 0102- 3098.

ALVES, G. L.; MAMEDE, S.. Quando uma pandemia expõe as limitações da escola e da educação ambiental formal. Revista Brasileira de Educação

Ambiental - Revbea, São Paulo, v. 15, n. 4, p. 175-189, 2020. ISSN: 1981-1764.

BENTO, A. V. Como fazer uma revisão da literatura: considerações teóricas e práticas. Revista da Associação Académica da Universidade da Madeira,

Funchal, n. 65, ano VII, p. 42-44, maio 2012. ISSN: 1647-8975.

BRASIL. (2012). Resolução no 02 de 15 de junho de 2012. Estabelece as

Diretrizes Curriculares Nacionais para a Educação Ambiental. Brasília-DF: Diário Oficial da União, 2012. Disponível em:

http://portal.mec.gov.br/dmdocuments/rcp002_12.pdf. Acesso em: 22 ago. 2020.

CAJUEIRO, R. L. P. Manual para elaboração de trabalhos acadêmicos: guia prático do estudante. 3. ed. [S. I.]: Vozes, 2012. 112 p. ISBN-10: 853264354X. ISBN-13: 978-8532643544.

CHASSOT, A. Alfabetização Científica - Questões e Desafios para a Educação. ljuí: Editora Unijuí. 3르ed. 2003.

DEMO, P.. Aprendizagens e novas tecnologias. Revista Brasileira de Docência, Ensino e Pesquisa em Educação Física, [s. I.], v. 1, n. 1, p. 53-75, ago. 2009. ISSN 2175-8093. Disponível em:

http://www.pucrs.br/famat/viali/doutorado/ptic/textos/80-388-1-PB.pdf. Acesso em: 22 ago. 2020.

DIAS, B. de C.; BOMFIM, A. M. do. A "teoria do fazer" em Educação Ambiental Crítica: uma reflexão construída em contraposição à Educação Ambiental Conservadora. In: Atas do Encontro Nacional de pesquisa em educação em ciências, 8. ed., 2011. Campinas: Associação Brasileira de Pesquisa em Educação em Ciências, 2011.

FIGUEIREDO, M. L.; GUERRA, A. F. S.; CARLETTO, D. L.. Ambientalização nas instituições de Educação Superior: reflexões do IV Seminário

Sustentabilidade na Universidade. In: RUSCHEINSKY, Aloisio (Org.).

Ambientalização nas Instituições de Educação Superior no Brasil. São Carlos:

EESC/USP, 2014. p. 337-349. ISBN: 978-85-8023-021-5.

FREITAS, D. M. da S. Na era da tecnologia ou da poluição: a educação

ambiental praticada nas escolas públicas do Distrito Federal. 2016. 115 f. Tese

(Doutorado em Educação em Ciências: Química da Vida e Saúde) -

Universidade Federal do Rio Grande do Sul. Porto Alegre, 2016.

GOHN, M. da G. Educação não formal e o educador social: atuação no desenvolvimento de projetos sociais. São Paulo: Cortez, 2016. 104 p. ISBN-10: 8524915935. ISBN-13: 978- 8524915932.

HENDGES, A. S. Educação Ambiental no Ensino Formal e Não Formal, Lei 9.795/1999. Ecodebate cidadania e meio ambiente, 2010. Disponível em: http://www.ecodebate.com.br/2010/09/13/educacao-ambiental-no-ensinoformale-nao-formallei-9-7951999-artigo-de-antonio-silvio-hendges. Acesso em: 22 ago. 2020.

INOCÊNCIO, A. F. Educação ambiental e educação não formal: um estudo de caso na perspectiva de um museu interdisciplinar. In: Anais do Seminário de pesquisa em educação da Região Sul, 9 ed., 2012. Caxias do Sul: Universidade 
de Caxias do Sul, 2012.

LOPES, J. S. L. Sobre os processos de "ambientalização" dos conflitos e sobre dilemas de participação. Horizontes Antropológicos, Porto Alegre, a. 12, n. 25, p. 31-64, 2006. e-ISSN: 1806-9983.

LOPES, P. A.; BUENO, F. P.; SAISSE, M. V. Contextos não escolares e pesquisa em educação ambiental: questões e desafios observados nos encontros de pesquisa em educação ambiental. (EPEAS). Pesquisa em Educação Ambiental, [s. I.], v. 13, n. 1, p. 196-207, 2018. DOI: http://dx.doi.org/10.18675/2177-580X.vol13.n1.p196-207.

MARTINS, B. T. A.; TEIXEIRA, C.; SOUSA, F. F. de. Centro de Educação Ambiental: um espaço não formal de Educação Ambiental na visão de professores das escolas estaduais de Itaúna - MG. Revista Eletrônica do Mestrado em Educação Ambiental, Rio Grande, v. 34, p. 320- 339, set./dez., 2017. ISSN: 1517-1256.

MARTINS, G. de A.; PINTO, R. L. Manual para elaboração de trabalhos acadêmicos. 1. ed. São Paulo: Atlas, 2001. 96 p. ISBN: 8522430047. ISBN-13: 9788522430048.

MIYAZAWA, G. C. M. C. A inserção da temática ambiental no curso de Licenciatura em Ciências Biológicas do Instituto Federal de Educação, Ciência e Tecnologia de São Paulo, Câmpus São Roque. 2018. Tese (Programa de PósGraduação em Ensino de Ciências e Matemática). Universidade Cruzeiro do Sul, São Paulo, 2018.

MONTANHIM, G. C.; CARON, M. F.; CINQUETTI, H. C. S. Aspectos linguísticos e Educação Ambiental na aprendizagem infantil. Pesquisa em Educação Ambiental, São Carlos-SP, v. 6, n. 2, p. 11-32, jul./dez. 2011. ISSN: 2177-580X. NARCIZO, K. R. S. Uma análise sobre a importância de trabalhar educação ambiental nas escolas. Revista Eletrônica do Mestrado em Educação Ambiental. v. 22, 2009. 86-94p.

OLIVEIRA, L.; NEIMAN, Z.. Educação Ambiental no Âmbito Escolar: Análise do Processo de Elaboração e Aprovação da Base Nacional Comum Curricular (BNCC). Revista Brasileira de Educação Ambiental - RevBEA, São Paulo, v. 15, n. 3, p. 36-52, 2020. ISSN: 1981-1764.

PRODANOV, C. C.; FREITAS, E. C. de. Metodologia do trabalho científico: métodos e técnicas da pesquisa e do trabalho acadêmico. 2. ed. Novo Hamburgo: Universidade Feevale, 2013. 277 p. ISBN: 978-85-7717-158-3. REIS, L.C.L.;

SEMÊDO, L.T.A.S.; GOMES, R.C. Conscientização Ambiental: Da Educação Formal a Não Formal. Revista Fluminense de Extensão Universitária, Vassouras, v. 2, n. 1, p. 47-60, jan/jun., 2012.

ROTHER, E. T. Revisão sistemática x revisão narrativa. Acta Paulista de Enfermagem, São Paulo, v. 20, n. 2, p. 5-6, 2007.

RUSCHEINSKY, A. (Org.). Ambientalização nas Instituições de Educação Superior no Brasil. São Carlos: EESC/USP, 2014. ISBN: 978-85-8023-021-5. SAUVÉ, L. Viver juntos em nossa terra: desafios contemporâneos da educação ambiental. Revista Contrapontos, Itajaí, v. 16, n. 2, mai.-ago. 2016.

SILVA, E. da. (Org.). Temas em ecologia e educação ambiental. Rio de Janeiro: Gramma, 2017. 236 p. ISBN-10: 8559682414. ISBN-13: 978-8559682410.

SILVA, L. N. da; GRYNSZPAN, D. A parceria educação formal - não formal para a apropriação da Química no cotidiano. In: Anais do X Encontro Nacional de Pesquisa em Educação em Ciências, 10. ed., 2015. Águas de Lindoia-SP: 
ABRAPEC, 2015.

SOARES, M. B.; FRENEDOZO, R. de C. Educação Ambiental: um estudo sobre a ambientalização no ensino fundamental. Revista De Ensino De Ciências E Matemática - Rencima. São Paulo, v. 10 n. 6, 2019 p. 95-113. DOl:

https://doi.org/10.26843/rencima.v10i6.2499.

VIEGAS, P. de L.; NEIMAN, Z. A prática de educação ambiental no âmbito do ensino formal: estudos publicados em revistas acadêmicas brasileiras. Revista Pesquisa em Educação Ambiental, São Paulo, v. 10, n. 2, p. 45-62, 2015. ISSN: 2177-580X. 